\title{
Evaluation of a novel progressive pharmaceutical care model based on inhaler technique in the disease management of patients with asthma and chronic obstructive pulmonary disease in China
}

\section{Wanqing Wang}

First Affiliated Hospital of Soochow University https://orcid.org/0000-0002-0608-8731

\section{Tao Xu}

First Affiliated Hospital of Soochow University

\section{Qiong Qin}

First Affiliated Hospital of Soochow University

\section{Liyan Miao}

First Affiliated Hospital of Soochow University

Jian'an Bao

First Affiliated Hospital of Soochow University

Rong Chen ( $\square$ rongchen_76@aliyun.com )

First Affiliated Hospital of Soochow University

\section{Research article}

Keywords: pharmaceutical care model, inhaler technique, patient intervention, asthma, COPD

Posted Date: November 25th, 2019

DOI: https://doi.org/10.21203/rs.2.17744/v1

License: (c) (1) This work is licensed under a Creative Commons Attribution 4.0 International License.

Read Full License 


\section{Abstract}

Background: Inhaler device is regarded as the standard treatment for patients with asthma and chronic obstructive pulmonary disease (COPD). However, patients still have errors in performing inhaler devices even after education and training. This study aimed to explore the effective of a novel progressive pharmaceutical care model based on inhaler technique in the disease management of asthma and COPD patients in China.

Methods: A prospective intervention study was conducted. 176 enrolled asthma and COPD patients were randomly divided into two groups: 88 in the intervention group and 88 in the control group. The novel progressive pharmaceutical care model included making a brochure, making videos, setting up special drug dispensing window for asthma and COPD patients, face to face demonstration and evaluation, online consultation, and follow up and reevaluation, which was provided for the intervention group participants lasted for 3 months, while the control group patients received usual pharmaceutical care (oral instruction of using inhaler devices was only provided). Outcome measures including rate of clinical effective, incidence of ' exacerbation ( $\geq 2$ times), medication adherence, inhaler technique score, rate of correct inhaler usage, and belief about medicines (BMQ) were used to evaluate the pharmaceutical care model. T test and $\chi 2$ test were used. Patient satisfaction in the intervention group was surveyed after 3 months.

Results: After 3 months' intervention, the rate of clinical effective, the Morisky Medication Adherence Scale (MMAS-8) score, the inhaler technique score and the rate of correct inhaler usage were higher and the incidence of exacerbation ( $\geq 2$ times) and the BMQ score were lower in the intervention group compared with the control group $(P<0.00)$. Besides, the item 1-4, and item 6-7 of patient satisfaction in the intervention group achieved at least $93.18 \%$.

Conclusions: The novel progressive pharmaceutical care model based on inhaler technique gave great improvement in the disease management of patients with asthma and COPD. It is proved to be valuable and worthy of further promotion.

\section{Introduction}

Asthma and COPD are common respiratory diseases, which are the main cause of high morbidity, heavy economic and social burden worldwide [1]. Disease management plays a key role in the long-term therapies of asthma and COPD. Though disease control could be achieved effectively among many patients through medication [2, 3], present treatment of asthma and COPD are not optimal among many patients [4]. Many factors could affect the disease management of asthma and COPD, such as adherence to prescribed medications, technique of using an inhaler, patients' perceptions and patient education $[5,6]$, and disease management failure predominantly due to the incorrect inhaler technique usage of patients [7]. 
Inhaled medication plays an important role in the medication therapy of asthma and COPD [1], but it is difficult for most asthma and COPD patients to operate inhaler devices correctly. Misuse of inhaler technique may lead to poor asthma and COPD managements $[4,8]$. The Global Initiative for Chronic Obstructive Lung Disease (GOLD) 2017 also firstly proposed that frequently incorrect usage of inhaler devices is the key factor that lead to poor treatment [9]. Furthermore, incorrect inhaler usage is associated with increasing emergency department visits and higher costs [10] and suboptimal asthma and COPD control [11].

Nowadays, the role of a pharmacist in disease management is becoming more and more important. With the development of health care reform, clinical pharmacy has also developed rapidly in China. However, there are thousands of outpatients every day in the large-scale and general hospitals, and the time for each patient to see a doctor is very limited. The medical policy of graded diagnosis and treatment is gradually being implemented in China. Graded diagnosis and treatment refers to grading according to the priority of the disease and the difficulty of treatment. Different levels of medical institutions are responsible for the treatment of different diseases, and gradually realize the medical process from general to specialized. Government encourages patients with chronic diseases to go to community hospitals, but most patients still choose large-scale and general hospitals first. Therefore, it is very necessary and valuable for pharmacists to provide effective and high-quality pharmaceutical care for patients. The present study was conducted to evaluate a novel progressive pharmaceutical care model based on inhaler technique in the management of asthma and COPD patients in China.

\section{Material And Methods}

\section{Study design}

This study was conducted at the First Affiliated Hospital of Soochow University, Suzhou, Jiangsu, China. Patients who visited respiratory department in the hospital and used inhaler devices were enrolled from September 2015 to June 2017. The study was conducted in accordance with the amended Declaration of Helsinki. A questionnaire was filled by the participant, including age, gender, educational status (no education, lower education, secondary education, or higher education), marital status (married or unmarried/divorced/solitary), medical insurance (yes or no), monthly income, smoking history (ever or never), drinking, diagnosis (asthma or COPD) and the type of inhaler device. The flowchart of this study was shown in Figure 1.

\section{Inclusion criteria and exclusion criteria}

Patients who meet the following criteria will be enrolled: diagnosed as asthma according to Global Initiative for Asthma (GINA) [12] or COPD according to GOLD criteria [3]; Suffering from the disease more than one month and using an inhaler device presently but did not receive any inhaler education; Aged between 18 and 75 years old; Patients could self-administer their medication and had no difficulty in 
communicating with Chinese; Willing to participate and accept subsequent follow-up; Did not involve in any other research. Patients who have one of the following conditions will not be enrolled: the patient is in an acute exacerbation; Using antibiotics within half a month; Bacterial infection in areas other than the respiratory system; Unstable angina pectoris or myocardial infarction occurred in the past 6 months; Suffering from severe liver or kidney dysfunction; Suffering from Coagulopathy; Suffering from connective tissue disease.

\section{Summarization and improvement of the inhaler technique}

We developed a 10-step inhaler technique according to a 7-step inhaler technique [13]. Considering the situation of inhaler usage in Chinese patients, we added three steps of sitting posture before the inhalation, cleaning and gargling after the inhalation [14]. Inhaler technique in this study was summarized into 10 simple steps according to the previous study, including sitting up, opening the device, loading drug, exhaling, biting, inhaling, holding one's breath, repeating, cleaning and gargling [14]. The total scores of the 10-step inhaler technique were 10 scores corresponding to the 10 steps. Each correct step was defined as " 1 score" and an incorrect or missed step was defined as "0 score". Each step of the inhaler technique performed by patients was evaluated using the 10-step inhaler technique in detail, which was shown in Table 1.

\section{Progressive pharmaceutical care model}

A pharmaceutical care model was established by combining six methods to train and educate patients with asthma and COPD progressively.

\section{Making a brochure}

A brochure was created after we conducted a survey of the information that asthma and COPD patients wanted to know. The contents of the brochure included etiology and symptoms of asthma and COPD, drug classification of asthma and COPD, correct usage of inhaler devices, and the explanation of the most common problems patients encountered when using devices. The brochure was provided for asthma and COPD patients free of charge.

Making Videos based on 10-step inhaler technique

Videos based on 10-step inhaler technique named "Correct Usage methods on inhaler devices" were created and free of charge to asthma and COPD patients. The videos were uploaded to our online 
consultation platform. Additionally, a two-dimensional code was printed on our medication list, and patients could watch the videos via scanning it by using a China's popular messaging app, WeChat. Patients could also watch the videos through the video APP on their mobile phone as well at any time if they want.

Setting up special drug dispensing window for asthma and COPD patients

The outpatient pharmacy of our hospital has many windows for drug dispensing, and one of these is specially designed for asthma and COPD patients. The information of patients diagnosed with asthma or COPD were automatically allocated to this drug dispensing window. The most frequently used demonstration devices of Turbuhaler, Diskus and Handihaler were provided on this window $₫$ Pharmacists used these devices to demonstrate correct inhaler technique for asthma and COPD patients. Patients could consult any questions associated with asthma and COPD on the drug dispensing window.

Face to face demonstration and evaluation

When asthma or COPD patients came to our drug dispensing window to collect their inhaler medicine, the specially trained pharmacists would educate and assess patients' medication face to face. Patients were required to show their inhaler technique by using demonstration devices, and this process was observed by the specially trained pharmacists. Each correct step of the inhaler technique demonstrated by patients was recorded, and the incorrect steps were also recorded. Besides, the specially trained pharmacists made an initial assessment for patients, which included medication adherence, incidence of exacerbation ( $\geq 2$ times), inhaler technique sore, rate of correct inhaler usage and belief bout medicines. After the evaluation, the same pharmacists demonstrated and explained the 10-step inhaler technique for patients by using demonstration devices, and the incorrect steps demonstrated by the patients were pointed up at the same time. This procedure continued for at least 5 minutes until no errors were made by the patients. Questions could also be asked by patients.

Online consultation

Various menu items were created in our WeChat Subscription, and one of which was used for online consultation for patients with asthma and COPD. If patients had confusion about the diseases of asthma and COPD or inhaler technique, they could consult our pharmacists by using this platform. Besides, popular science articles related with asthma and COPD were offered regularly in our WeChat Subscription for patients to acquire popular science knowledge. 
Telephone follow-up was made to all the participants once a month by the specially trained pharmacists, and the follow-up was conducted three times. Each telephone conversation time was less than 5 minutes. The pharmacists re-educated patients if they still operated the inhaler devices incorrectly during the first two follow-up. Additionally, patients could also ask questions if they had confusion. During the third telephone follow-up, the pharmacists re-evaluated the patients by talking to them over the phone. The assessment included the rate of clinical effective, the incidence of exacerbation ( $\geq 2$ times), medication adherence, inhaler technique score, the rate of correct inhaler usage and belief about medicines. Patient satisfaction in the intervention group participants was also investigated.

\section{Outcome measures}

Rate of clinical effective

Disease control was assessed by Asthma Control Test (ACT) score [15] or COPD Assessment Test (CAT) score [16]. The total ACT scores are 25 points, and asthma patients have an ACT score $\geq 20$ indicates effective in clinical treatment. The total CAT scores are 40 points. Patients with COPD with a variation in CAT score by 2 points or more indicates effective in clinical treatment [16]. The rate of clinical effective is considered as the number of patients who acquired complete and partial control accounts for the number of total patients in the intervention group or control group. The rate of clinical effective was assessed after 3 months' intervention

Incidence of exacerbation ( $\geq 2$ times)

The incidence of exacerbation ( $\geq 2$ times) is considered as the number of exacerbations ( $\geq 2$ times) accounts for the number of total patients in the intervention group or control group. The incidence of exacerbation ( $\geq 2$ times) before and after 3 months' intervention was evaluated.

\section{Medication adherence}

The medication adherence of patients was evaluated according to the MMAS-8 [17]. The MMAS-8 contains 8 questions. The answer "no" is defined as " 1 score" and "yes" is defined as " 0 score" corresponding with the item 1 to 4 , and 6 to 7 . The item 5 is reverse scored, and the answer "yes" is defined as " 1 score" and "no" is defined as " 0 score". The question-8 is scored based on a 5 -point Likert scale, and the answer "never/almost never" is defined as "4 scores", and the answer "always" is defined as " 0 score". The total scores are the sum of the scores of the 8 questions, and the highest score is 11 scores. The total score that below 6 is considered low adherence, and between 6 and 7 is considered 
medium adherence, and above 8 is considered high adherence. The MMAS-8 score was evaluated before and after 3 months' intervention.

Inhaler technique score

Patients' inhaler usage was evaluated and re-educated based on the 10-step inhaler technique when the monthly follow-up was conducted. After 3 months' intervention, patients' inhaler technique was scored on the last telephone follow-up, and the result was compared to the inhaler technique score result before intervention.

\section{Rate of correct inhaler usage}

The rate of correct inhaler usage was defined as the percentage of patients who use the inhaler devices correctly. The rate of correct inhaler usage of each individual step was evaluated before and after 3 months' intervention.

\section{Belief bout medicines}

Patients' belief about medicines was assessed according to the questionnaire on belief about medicine (BMQ) [18]. The BMQ is a 9-item questionnaire. The answer "yes" is defined as " 1 score" and "no" is defined as " 0 score". The total score is the sum of the scores of all items. A higher total score indicates a stronger negative belief in drug. The BMQ score was evaluated before and after 3 months' intervention.

\section{Patient satisfaction}

A satisfaction questionnaire was designed according to a previous research [19] and the properties of the present study population. The satisfaction questionnaire consisted of 8 questions. The response option for the question 1-7 was "yes" or "no". The answer "yes" is defined as " 1 score" and "no" is defined as " 0 score". The answer for the eighth question was optional. Patient satisfaction was evaluated in the intervention group after 3 months' intervention.

\section{Data Analysis}


Data was analyzed by using the Statistical Package for Social Science (SPSS) software (version 19, SPSS, Chicago, Illinois), and was presented as the mean \pm standard deviation (sd) or percentages. $T$ test and $\chi^{2}$ test were used for the comparison between the intervention group and control group. Differences with $\mathrm{P}<0.05$ were considered statistically significant.

\section{Results}

\section{Patients' demographic characteristics}

Among the 176 enrolled participants, 135 patients used Tubuhaler, 33 patients used Diskus and 18 patients used HandiHaler. Recruited patients were divided randomly into two groups: 88 in the intervention group and 88 in the control group. The progressive pharmaceutical care model was provided to the intervention group patients, and usual pharmaceutical care (oral instruction of using inhaler devices) was provided to the control group patients. There was no significant difference in the demographic characteristics of the patients between the two groups at baseline $(P>0.05)$. Patients' demographics and clinical characteristics were presented in Table 2.

\section{Rate of clinical effective}

74 out of 88 patients in the intervention group and 51 out of 88 patients in the control group achieved complete and partial control after 3 months' intervention. The rate of clinical effective was $84.09 \%$ in the intervention group, significantly higher than the results of $57.95 \%$ in the control group $(P<0.001)$. The results were shown in Table 3.

\section{Incidence of exacerbation ( $\geq 2$ times)}

Before intervention, there was no significant difference in the incidence of exacerbation ( $\geq 2$ times) between the two groups. After intervention, the incidence of exacerbation ( $\geq 2$ times) in the intervention group significantly decreased compared with the control group $(P=0.042)$. The results were depicted in Table 4

\section{Medication adherence}

Poor medication adherence was determined in the two groups at baseline. After intervention, the medication adherence improved significantly in the intervention group compared with the control group. The MMAS-8 score was $9.39 \pm 1.95$ (mean $\pm s d$ ) in the intervention group and $7.38 \pm 2.54$ (mean $\pm s d$ ) in the control group $(P<0.001)$. The results were presented in Table 5. 


\section{Inhaler technique score}

Patients' inhaler technique was significantly improved during the intervention period. No significant difference was found between the two groups in the inhaler technique score before intervention. After the pharmaceutical care services were conducted, the inhaler technique score reached $9.53 \pm 0.83$ (mean \pm sd) in the intervention group, while the score was only $7.01 \pm 1.68$ (mean $\pm s d$ ) in the control group. The difference between the two groups was statistically significant $(P<0.001)$, and the results were depicted in Table 6.

\section{Rate of correct inhaler usage}

At baseline, there was no significant difference in the rate of correct inhaler usage for each individual step between the two groups. When compared with the control group patients, the proportion of the intervention participants who operated step 1-4 and 7-10 correctly was significantly higher at the end of the study $(P<0.05)$. Besides, the percentage of correct inhaler usage of step 6 had a tendency of significant difference between the two groups $(P=0.051)$. The results were presented in Table 7 .

\section{Belief about medicines}

BMQ was used to evaluate patients' concerns about the harm results caused by using medication. The higher score indicates the patients' stronger negative attitudes to medications. Initially, patients in the two groups both had a strong negative belief in drug, and BMQ scores between the two groups had no significant difference. However, patients' perceptions of adverse effects of medication improved significantly throughout the research period, and the BMQ score was 2.15 \pm 2.14 (mean \pm sd) in the intervention group, significantly lower than the results of $7.02 \pm 1.91$ (mean $\pm s d$ ) in the control group $(P<0.00)$. The results were presented in Table 8.

\section{Patient satisfaction}

The patient satisfaction in the intervention group was investigated at the end of the study. The survey results revealed that item 1-4 and 6-7 reached above $93.18 \%$, demonstrating that the participants were very satisfied with the novel progressive pharmaceutical care model. The results were depicted in Table 9.

\section{Discussion}


The present study practiced and evaluated a novel progressive pharmaceutical care model based on inhaler technique in patients with asthma and COPD.

Firstly, we summarized and improved the inhaler technique. A 7-step inhaler technique was introduced from England. When using inhaler devices, improper posture can cause trachea flexion and narrowing, and reduce deposition rate in lung. The residual saliva on the device will make the powder deliquescence and reduce the amount of suction each time. Besides, drugs are still deposited in the oropharynx after inhalation. These steps and key technique points will affect the efficacy and adverse reactions of inhaled drug delivery. So, we included three important steps in the standard operating procedures of inhaled medication, which included sit straight before the medication, cleaning and gargling after the inhalation. Such 10-step inhaler technique was firstly applied in the usage of inhaler devices. It was not only provided convenience of memorizing and utilizing for patients, but also in favor of pharmacists for consolidated evaluation of inhaler technique of patients.

We used the 10-step inhaler technique to instruct and score patients' inhaler medication, and the results showed that patients' inhaler technique score improved obviously. Before intervention, the inhaler technique scores were both low in the intervention group and the control group. After intervention, the inhaler technique score achieved $9.53 \pm 0.83$ (mean $\pm \mathrm{sd}$ ) in the intervention group, significantly higher than the result of $7.01 \pm 1.68$ (mean $\pm \mathrm{sd}$ ) in the control group. Some researches [1, 2] also came to the similar conclusion. The rate of correct inhaler usage of each individual step was also detected. At baseline, about 30-40\% patients failed to operate inhaler device correctly, including step 1 (sit up straight and keep the upper part of the body upright), step 7 (hold breath for 10 seconds or longer as far as possible), step 8 (repeat the fifth step to the seventh step if necessary), step 9 (clean the place where the mouth is bitten on the device and close inhaler) and step 10 (gargle deeply and then spit out the mouthwash). The most problematic step was step 7 (hold breath for 10 seconds or longer as far as possible), and only less than $50 \%$ patients could operate this step correctly. Failure in these steps could reduce pharmacological effect and cause insufficient drug dose delivered to lung [20], and lead to adverse effects such as immunosuppression reaction generated by inhaled corticosteroids in oral cavity [21]. After intervention, the rate of correct inhaler usage of each individual step in the intervention group significantly improved, except for step 5 (place mouthpiece between teeth and lips) and step 6 (inhale forcefully and deeply). This probably due to that the rate of correct inhaler usage of step 5 was already very high (above 90\%) initially. The rate of correct inhaler usage of step 6 between the two groups tend to statistically difference $(P=0.051)$. Besides, the rate of correct inhaler usage of all steps achieved in above $93.00 \%$ apart from step 7 (hold breath for 10 seconds or longer as far as possible). However, the rate of correct usage of step 7 increased from $45.45-86.36 \%$ in the intervention group. It was less than $93.00 \%$, but the improvement was obvious. These results further illustrated the necessity of adding step 1, step 9 and step 10. In previous research, the correct percentage of inhalation usage also increased after intervention [1, 22-23]. What's more, we made videos by demonstrating the correct inhaler technique usage based on 10-step inhaler technique. A two-dimensional code was printed on our medication list, and patients can watch the videos by scanning the two-dimensional code. Additionally, we also made an educational brochure about asthma and COPD. 
Then, we provided a novel progressive pharmaceutical model for the asthma and COPD patients in the intervention group. The information of patients diagnosed with asthma or COPD was automatically allocated to our special drug dispensing window for asthma or COPD patients. When patients with asthma or COPD came to collect their inhaler medicine, the specially trained pharmacists would educate and assess patients' inhaler medication face to face. At beginning, patients were required to demonstrate their inhaler technique operation and the specially trained pharmacists conducted an initial assessment. After that, the pharmacists educated and instructed patients to operate the inhaler devices correctly face to face. At the same time, pharmacists made an evaluation for patients again. The evaluation outcomes included the incidence of exacerbation ( $\geq 2$ times), inhaler technique sore, the rate of correct inhaler usage, medication adherence and belief bout medicines. Patients could watch the brochure or videos at home after they leave hospital. Besides, they could also consult our pharmacists through the online consultation platform or come to our special drug dispensing window. What's more, follow up once a month provided an opportunity for pharmacist to evaluate and reeducate patients' inhaler technique usage. Finally, we would make a reevaluation for patients during the third telephone follow-up. After three months' intervention, the rate of clinical effective increased from $57.95-84.09 \%$ in the intervention group, significantly higher than the result of $54.55 \%$ in the control group. Considering that there were only 33 COPD patients in this study, we did not analyze the rate of clinical effective for patients with asthma vs COPD. Initially, the mean level of medication adherence was not high whether in the intervention group (7.32 \pm 2.82 , mean $\pm s d)$ or in the control group $(7.18 \pm 3.10$, mean $\pm s d)$. After intervention, patients' medication adherence in the intervention group obviously increased from $7.32 \pm 2.82$ (mean \pm sd) to 9.39 \pm 1.95 (mean $\pm \mathrm{sd}$ ). In addition, the incidence of exacerbation ( $\geq 2$ times) decreased from $35.23-14.77 \%$ in the intervention group, significantly lower than that $(27.27 \%)$ in the control group $(P=0.042)$. Patients' belief about medicines could be a predictor of adherence [6]. Patients' attitude toward medications also improved during the study period. The BMQ score decreased from $7.47 \pm 1.47$ (mean \pm sd) to $2.15 \pm 2.14$ (mean $\pm \mathrm{sd}$ ) in the intervention group, revealing that patient perceptions significantly improved after intervention.

Finally, we investigated patient satisfaction in the intervention group who received progressive pharmaceutical care. Patient satisfaction can be considered as the overlap of a patient's experience compared with their expectations, and satisfied patients are more likely to adhere to their disease management [19]. The percentage of patients who were satisfied with the pharmaceutical care model achieved at least $93.18 \%$, except for item 5 (77.27\%, My knowledge about diseases of asthma and COPD and medications improved after receiving the services) and item $8(63.64 \%$, I have some suggestions about the pharmaceutical care services).

In summary, these results in the study revealed that the patients in the intervention group showed better compliance with inhaler devices usage, higher rate of clinical effective, inhaler technique score, rate of correct inhaler usage and lower incidence of exacerbation ( $\geq 2$ times) and belief about medications. This pharmaceutical care mode met the needs of asthma and COPD patients, and reflected the value of pharmacist's work. Nevertheless, the limitation of the present study was that the number of participants is not enough, and a larger controlled study might be needed. 


\section{Conclusion}

In China, more and more pharmacists are actively involved in the management of chronic diseases. The present research evaluated the value of a novel progressive pharmaceutical care model in improving the disease management of asthma and COPD patients and the results were inspiring. In the future, it might be widely promoted and offer references to more hospitals in China, even in other developing countries.

\section{Abbreviations}

COPD: chronic obstructive pulmonary disease; MMAS-8:Morisky Medication Adherence Scale; BMQ:belief about medicine; GOLD:The Global Initiative for Chronic Obstructive Lung Disease; GINA:Global Initiative for Asthma; ACT:Asthma Control Test; CAT:COPD Assessment Test; SPSS:Statistical Package for Social Science.

\section{Declarations}

\section{Acknowledgements}

We acknowledge the staff of outpatient pharmacy in our hospital who supported us to conduct this study.

\section{Author contributions}

Rong Chen takes responsibility for the content of the manuscript. Rong Chen provided the conception and design of the study. Wanqing Wang and Tao Xu drafted the article and revised it critically for important intellectual content. Qiong Qin made the contribution of acquisition of data and analysis and interpretation of data. Rong Chen final approved the version of the article to be published. Liyan Miao and Jian'an Bao agreed to be accountable for all aspects of the work in ensuring that questions related to the accuracy or integrity of the work are appropriately investigated and resolved. All authors have reviewed the manuscript and have approved the final article should be true.

\section{Funding}

This work was supported by the National Health and Family Planning Commission of PRC; the Development Center for Medical Science and Technology of National Health and Family Planning Commission of the People's Republic of China (grant number 2017ZX09304-021); and the Jiangsu Pharmaceutical Association (grant number Q2018153). The funding sources had no involvements in the study design, the collection, analysis or interpretation of the data, the writing of the report, or the decision to submit this article for publication. 


\section{Availability of data and materials}

The datasets used and analyzed during the current study are available from the corresponding author on reasonable request.

\section{Ethics approval and consent to participate}

The study was approved by the ethics committee of the First Affiliated Hospital of Soochow University, and written informed consent was obtained from all patients.

\section{Consent for publication}

Not applicable.

\section{Competing interests}

All authors report no conflicts of interest in this work.

\section{References}

1. Dudvarski-llic A. Zugic V, Zvezdin B, Kopitovic I, Cekerevac I, Cupurdija V, et al. Influence of inhaler technique on asthma and COPD control: a multicenter experience. Int J Chronic Obstr. 2016;11.

2. Basheti IA, Obeidat NM, Reddel HK. Effect of novel inhaler technique reminder labels on the retention of inhaler technique skills in asthma: a single-blind randomized controlled trial. NPJ Prim Care Respir Med. 2017;27.

3. Global initiative for chronic obstructive lung disease (GOLD). Global Strategy for the diagnosis, management, and prevention of COPD. Available from: http://www.goldcopd.org/. 2014.

4. Pothirat $\mathrm{C}$, Chaiwong $\mathrm{W}$, Phetsuk $\mathrm{N}$, et al. Evaluating inhaler use technique in COPD patients. Int J Chron Obstruct Pulmon Dis. 2015;10.

5. Topp M, Vestbo J, Mortensen EL. Psychometric Properties of the COPD-Specific Beliefs About Medicine Questionnaire in an Outpatient Population: A Rasch-Analysis. Chronic Obstr Pulm Dis. 2016;3(4).

6. Fischer W, Brandstetter S, Brandl M, Finger T, Böhmer MM, Pfeifer M, et al. Specific, but not general beliefs about medicines are associated with medication adherence in patients with COPD, but not 
asthma: Cohort study in a population of people with chronic pulmonary disease. J Psychosom Res. 2018;107.

7. Bosnic-Anticevich SZ, Sinha H, So S, Reddel HK. Metered-dose inhaler technique: the effect of two educational interventions delivered in community pharmacy over time. J Asthma. 2010;47(3).

8. Cochrane MG, Bala MV, Downs KE, Mauskopf J, Ben-Joseph RH. Inhaled corticosteroids for asthma therapy: patient compliance, devices, and inhalation technique. Chest. 2000;117.

9. Global Initiative for Chronic Obstructive Lung Disease (GOLD). From the global strategy for the diagnosis, management and prevention of COPD. 2017. Available from: http://www.goldcopd.org/.

10. Giraud V, Roche N. Misuse of corticosteroid metered-dose inhaler is associated with decreased asthma stability. Eur Respir J. 2002;19.

11. Man KN, Tian Z, Lam DC, Wan JMF, Tan-Un KC. Satisfaction, preference and error occurrence of three dry powder inhalers as assessed by a cohort naïve to inhaler operation. Int $\mathrm{J}$ Chron Obstruct Pulmon Dis. 2018;13.

12. Global Initiative for Asthma (GINA). Global strategy for asthma management and prevention. Available from: http:// www.ginasthma.org/.

13. Reznik ML, Silver EJ, Cao Y. Evaluation of MDI-spacer utilization and technique in caregivers of urban minority children with persistent asthma [J]. J asthma. 2014;51(2).

14. Qiong Qin, Rong Chen, Wei Lei, Yicong Bian, Baochen Gu, Jian'an Bao. Evaluation and analysis of inhaler drug device adherence in asthma and COPD patients. Chinese Pharmaceutical Journal. 2016;5.

15. Nathan R A, Sorkness C A, Kosinski M, Schatz M, Li JT, Marcus P, et al. Development of the asthma control test: a survey for assessing asthma control. J Allergy Clin Immunol. 2004;113(1).

16. Liu T, Cai B Q. A New health quality of life questionnaire chronic obstructive pulmonary disease assessment test. Acta AcadMed Sine. 2010;32(2).

17. Chen H Z, Liu G W. Practical internal medicine. 13th ed. Beijing: People's medicine publishing house, 2009:15977.

18. Horne R, Weinman J, Hankins M. The beliefs about medicines questionnaire: The development and evaluation of a new method for assessing the cognitive representation of medication. Health Psychol. 1999;14(1).

19. Apikoglu-Rabus S, Yesilyaprak G, Izzettin FV. Drug-related problems and pharmacist interventions in a cohort of patients with asthma and chronic obstructive pulmonary disease. Respir Med. 2016;120.

20. Newman SP, Busse WW. Evolution of dry powder inhaler design, formulation, and performance. Respir Med. 2002;96.

21. Lavorini F, Magnan A, Dubus JC, Voshaar T, Corbetta L, Broeders M, et al. Effect of incorrect use of dry powder in halers on management of patients with asthma and COPD. Respir Med. 2008;102.

22. van 't Veer NE, Lameijer W, De Ley M, Toben FM. Teaching to inhale: better utilization of powder inhalators after counseling and instruction. Ned Tijdschr Geneeskd. 2001;145(5). 
23. Poudel RS, Piryani RM, Shrestha S, Prajapati A. Benefit of hospital pharmacy intervention on the current status of dry powder inhaler technique in patients with asthma and COPD: a study from the Central Development Region. Nepal. Integr Pharm Res Pract. 2016;6.

\section{Tables}


Table 1 Checklist of ten steps for inhaler technique assessment

\begin{tabular}{|c|c|c|}
\hline Step No. & Summary & Step Statement \\
\hline Turbuhaler & & \\
\hline 1 & sitting & sit up straight, and keep the upper part of the body upright \\
\hline 2 & opening & open the device by remove the cap from inhaler \\
\hline 3 & loading & rotate grip anti-clockwise and then back until a click is heard \\
\hline 4 & exhaling & exhale to residual volume, and away from device \\
\hline 5 & biting & place mouthpiece between teeth and lips \\
\hline 6 & inhaling & inhale forcefully and deeply \\
\hline 7 & holding & hold breath for 10 seconds or longer as far as possible \\
\hline 8 & repeating & $\begin{array}{l}\text { repeat the fourth step to the seventh step to ensure get the full } \\
\text { dose }\end{array}$ \\
\hline 9 & cleaning & $\begin{array}{l}\text { clean the place where the mouth is bitten on the device and close } \\
\text { inhaler }\end{array}$ \\
\hline 10 & gargling & gargle deeply and then spit out the mouthwash \\
\hline
\end{tabular}

\section{Diskus}

\begin{tabular}{|c|c|c|}
\hline 1 & sitting & sit up straight, and keep the upper part of the body upright \\
\hline 2 & opening & open inhaler \\
\hline 3 & loading & push lever back completely \\
\hline 4 & exhaling & exhale away from mouthpiece \\
\hline 5 & biting & place mouthpiece between teeth and lips \\
\hline 6 & inhaling & inhale forcefully and deeply \\
\hline 7 & holding & hold breath for 10 seconds or longer as far as possible \\
\hline 8 & repeating & $\begin{array}{l}\text { repeat the fourth step to the seventh step to ensure get the full } \\
\text { dose }\end{array}$ \\
\hline 9 & cleaning & $\begin{array}{l}\text { clean the place where the mouth is bitten on the device and close } \\
\text { inhaler }\end{array}$ \\
\hline 10 & gargling & gargle deeply and then spit out the mouthwash \\
\hline
\end{tabular}

\section{Handihaler}

\begin{tabular}{|c|c|c|}
\hline 1 & sitting & ht, and keep the upper part of the body upright \\
\hline 2 & opening & $\begin{array}{l}\text { open the inhaler by pulling the dust cap upwards, and open the } \\
\text { mouthpiece }\end{array}$ \\
\hline 3 & loading & $\begin{array}{l}\text { place the capsule in the center chamber and close the } \\
\text { mouthpiece firmly until the capsule rattle is heard }\end{array}$ \\
\hline 4 & exhaling & exhale away from mouthpiece \\
\hline 5 & biting & place mouthpiece between teeth and lips \\
\hline 6 & inhaling & inhale forcefully and deeply \\
\hline 7 & holding & hold breath for 10 seconds or longer as far as possible \\
\hline 8 & repeating & $\begin{array}{l}\text { repeat the fourth step to the seventh step to ensure get the full } \\
\text { dose }\end{array}$ \\
\hline 9 & cleaning & $\begin{array}{l}\text { clean the place where the mouth is bitten on the device and close } \\
\text { inhaler }\end{array}$ \\
\hline & gargling & gargle deeply and then spit out the mouthwash \\
\hline
\end{tabular}


Table 2 Characteristic of asthma and COPD patients $(n=176)$

\begin{tabular}{|c|c|c|c|c|}
\hline Characteristics & $\begin{array}{c}\text { Intervention group } \\
(\mathrm{n}=88)\end{array}$ & $\begin{array}{c}\text { Control group } \\
(\mathrm{n}=88)\end{array}$ & $t\left(x^{2}\right)$ & $\bar{P}$ \\
\hline Age (years) (mean \pm sd) & $46.3 \pm 14.5$ & $47.5 \pm 16.6$ & -0.51 & 0.61 \\
\hline Gender & & & 0.092 & 0.762 \\
\hline male & $41(46.59 \%)$ & $39(44.32 \%)$ & & \\
\hline female & $47(53.41 \%)$ & $49(55.68 \%)$ & & \\
\hline Education status & & & 0.276 & 0.964 \\
\hline no education & 1 & 1 & & \\
\hline lower education & 39 & 40 & & \\
\hline secondary education & 19 & 21 & & \\
\hline higher education & 29 & 26 & & \\
\hline Marital status & & & 0.487 & 0.485 \\
\hline married & 79 & 76 & & \\
\hline unmarried/divorced/solitary & 9 & 12 & & \\
\hline Medical insurance & & & 0.903 & 0.342 \\
\hline yes & 80 & 76 & & \\
\hline no & 8 & 12 & & \\
\hline Monthly Income & & & 1.2 & 0.549 \\
\hline$<3000$ & 17 & 23 & & \\
\hline $3000-6000$ & 36 & 34 & & \\
\hline$>6000$ & 35 & 31 & & \\
\hline Smoking history & & & 0.036 & 0.85 \\
\hline ever & 17 & 18 & & \\
\hline never & 71 & 70 & & \\
\hline Drinking & & & 0.044 & 0.834 \\
\hline yes & 13 & 14 & & \\
\hline no & 75 & 74 & & \\
\hline Diagnosis & & & 1.828 & 0.176 \\
\hline asthma & 75 & 68 & & \\
\hline COPD & 13 & 20 & & \\
\hline Type of inhaler device & & & 0.273 & 0.872 \\
\hline Tubuhaler & 68 & 67 & & \\
\hline Diskus & 12 & 11 & & \\
\hline HandiHaler & 8 & 10 & & \\
\hline
\end{tabular}

Table 3 Comparison of the rate of clinical effective between intervention group and control group after 3 months' intervention $(n=88)$

\begin{tabular}{cccc}
\hline $\begin{array}{c}\text { Assessment of the rate of } \\
\text { clinical effective }\end{array}$ & $\begin{array}{c}\text { Complete and partial } \\
\text { control (n) }\end{array}$ & $\begin{array}{c}\text { Rate of clinical } \\
\text { effective (\%) }\end{array}$ & P \\
\hline Intervention group $(\mathrm{n}=88)$ & 74 & $84.09 \%$ & $<0.001$ \\
Control group $(\mathrm{n}=88)$ & 51 & $57.95 \%$ & \\
\hline
\end{tabular}


Table 4 Comparison of incidence of exacerbation $\square \geq 2$ times between intervention group and control group after 3 months' intervention $(\mathrm{n}=176)$

Intervention

Baseline before intervention

3 months after intervention
Intervention group

$(\mathrm{n}=88)$

$31(35.23 \%)$

$13(14.77 \%)$
Control group

$(\mathrm{n}=88)$

$30(34.09 \%)$

$24(27.27 \%)$
0.87 0.042

Table 5 Comparison of MMAS-8 score between intervention group and control group $(\mathrm{n}=176)$

\begin{tabular}{lccc}
\hline Assessment of MMAS-8 & $\begin{array}{c}\text { Intervention group } \\
(\mathbf{n}=\mathbf{8 8})\end{array}$ & $\begin{array}{c}\text { Control group } \\
(\mathbf{n}=\mathbf{8 8})\end{array}$ & $\mathbf{P}$ \\
\hline $\begin{array}{l}\text { Baseline before } \\
\text { intervention }\end{array}$ & $7.32 \pm 2.82$ & $7.18 \pm 3.10$ & 0.96 \\
$\begin{array}{l}3 \text { months after } \\
\text { intervention }\end{array}$ & $9.39 \pm 1.95$ & $7.38 \pm 2.54$ & $<0.001$ \\
\hline
\end{tabular}

Table 6 Comparison of inhaler technique score between intervention group and control group ( $\mathrm{n}=176)$

\begin{tabular}{|c|c|c|c|}
\hline $\begin{array}{l}\text { Assessment of inhaler } \\
\text { technique }\end{array}$ & $\begin{array}{c}\text { Intervention group } \\
(\mathrm{n}=88)\end{array}$ & Control group $(n=88)$ & $\mathbf{P}$ \\
\hline Baseline before & $7.06 \pm 1.66$ & $6.74 \pm 1.63$ & 0.30 \\
\hline $\begin{array}{l}\text { intervention } \\
3 \text { months after } \\
\text { intervention }\end{array}$ & $9.53 \pm 0.83$ & $7.01 \pm 1.68$ & $<0.001$ \\
\hline
\end{tabular}


Table 7 Comparison of the rate of correct inhaler usage of each individual step between intervention group and control group $(n=176)$

\begin{tabular}{lcccc}
\hline $\begin{array}{l}\text { Assessment of the rate of correct } \\
\text { inhaler usage }\end{array}$ & $\begin{array}{c}\text { Intervention group } \\
\text { (n=88) }\end{array}$ & $\begin{array}{c}\text { Control group } \\
\text { (n=88) }\end{array}$ & $\mathbf{\chi}^{\mathbf{2}}$ & P \\
\hline $\begin{array}{l}\text { step 1 } \\
\text { Baseline before intervention }\end{array}$ & $68.18 \%(60)$ & $62.50 \%(55)$ & 0.627 & 0.428 \\
\hline 3 months after intervention & $97.73 \%(86)$ & $65.91 \%(58)$ & 27.844 & $<0.001$ \\
\hline step 2 & & & & \\
\hline Baseline before intervention & $70.45 \%(62)$ & $73.86 \%(65)$ & 0.255 & 0.614 \\
\hline 3 months after intervention & $96.59 \%(85)$ & $81.82 \%(72)$ & 8.496 & $\mathbf{0 . 0 0 4}$ \\
\hline step 3 & & & & \\
\hline Baseline before intervention & $84.09 \%(74)$ & $86.36 \%(76)$ & 0.181 & 0.671 \\
\hline 3 months after intervention & $97.73 \%(86)$ & $88.64 \%(78)$ & 4.382 & $\mathbf{0 . 0 3 6}$ \\
\hline step 4 & & & & \\
\hline Baseline before intervention & $72.73 \%(64)$ & $63.64 \%(56)$ & 1.676 & 0.195 \\
\hline 3 months after intervention & $96.59 \%(85)$ & $68.18 \%(60)$ & 22.553 & $<0.001$ \\
\hline step 5 & & & & \\
\hline Baseline before intervention & $90.90 \%(80)$ & $95.45 \%(84)$ & 0.805 & 0.37 \\
\hline 3 months after intervention & $98.86 \%(87)$ & $96.59 \%(85)$ & 0.256 & 0.613 \\
\hline step 6 & & & & \\
\hline Baseline before intervention & $90.91 \%(80)$ & $87.50 \%(77)$ & 0.531 & 0.466 \\
\hline 3 months after intervention & $96.59 \%(85)$ & $87.50 \%(77)$ & 3.802 & 0.051 \\
\hline step 7 & & & & \\
\hline Baseline before intervention & $45.45 \%(40)$ & $43.18 \%(38)$ & 0.092 & 0.762 \\
\hline 3 months after intervention & $86.36 \%(76)$ & $44.32 \%(39)$ & 34.347 & $<0.001$ \\
\hline step 8 & & & & \\
\hline Baseline before intervention & $59.09 \%(52)$ & $48.86 \%(43)$ & 1.853 & 0.173 \\
\hline 3 months after intervention & $93.18 \%(82)$ & $53.41 \%(47)$ & 37.417 & $<0.001$ \\
\hline step 9 & $64.77 \%(57)$ & $63.64 \%(56)$ & 0.025 & 0.875 \\
\hline Baseline before intervention & $94.32 \%(83)$ & $62.50 \%(55)$ & 26.313 & $<0.001$ \\
\hline 3 months after intervention & $52.27 \%(46)$ & $51.12 \%(45)$ & 0.023 & 0.88 \\
\hline step 10 & $93.18 \%(82)$ & $55.68 \%(49)$ & 32.513 & $<0.001$ \\
\hline Baseline before intervention & & &
\end{tabular}


Table 8 Comparison of BMQ score between intervention group and control group $(n=176)$

\begin{tabular}{|c|c|c|c|}
\hline Intervention & intervention group $(n=88)$ & $\begin{array}{l}\text { control group } \\
(\mathrm{n}=88)\end{array}$ & $\bar{P}$ \\
\hline Baseline before & $7.47 \pm 1.47$ & $7.40 \pm 1.96$ & 0.76 \\
\hline $\begin{array}{l}3 \text { months after } \\
\text { intervention }\end{array}$ & $2.15 \pm 2.14$ & $7.02 \pm 1.91$ & $<0.001$ \\
\hline
\end{tabular}

Table 9 Patient Satisfaction Survey in the intervention group after 3 months' intervention $(n=88)$

\begin{tabular}{lc}
\hline Items & $\mathbf{n ~ ( \% )}$ \\
\hline $\begin{array}{l}\text { 1 I have not received such a service from outpatient } \\
\text { department before }\end{array}$ & $85(96.59 \%)$ \\
2 I am satisfied with the pharmaceutical care services given & $87(98.86 \%)$ \\
by the pharmacist & $86(97.73 \%)$ \\
\hline I feel comfortable communicate with the pharmacist & $86(97.73 \%)$ \\
$\begin{array}{l}\text { 4 I am satisfied with the pharmacist answered questions I } \\
\text { have about my medications }\end{array}$ & $68(77.27 \%)$ \\
$\begin{array}{l}\text { 5 My knowledge about diseases of asthma and COPD and } \\
\text { medications improved after receiving the services }\end{array}$ & $86(97.73 \%)$ \\
$\begin{array}{l}\text { 6 I will recommend this service to my friends and family } \\
\text { members who are using inhaler devices }\end{array}$ & $82(93.18 \%)$ \\
\hline $\begin{array}{l}\text { other diseases } \\
\text { 8 I have some suggestions about the pharmaceutical care } \\
\text { services }\end{array}$ & $56(63.64 \%)$ \\
\hline
\end{tabular}

\section{Figures}




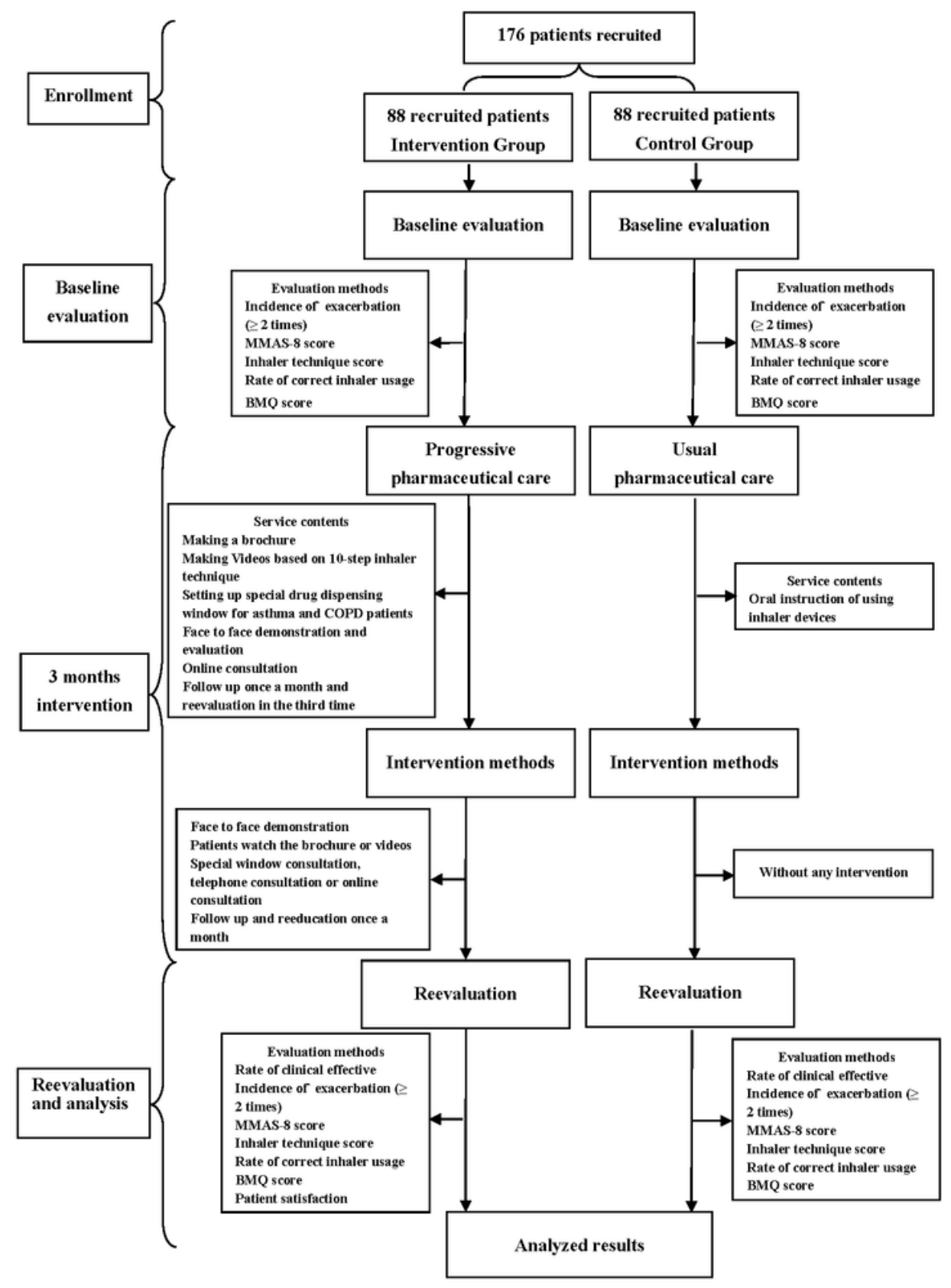

Figure 1

The design flowchart of the study. 